\title{
Correction to: A Multicenter, Observational, Prospective Study of the Effectiveness of Switching from Budesonide/Formoterol Turbuhaler ${ }^{\circledR}$ to Budesonide/Formoterol Easyhaler ${ }^{\circledR}$
}

Jörgen Syk · Ines Vinge · Mikael Sörberg · Mikko Vahteristo •

Paula Rytilä (D)

Received: February 22, 2019 / Published online: June 9, 2019

(C) The Author(s) 2019

Correction to: Adv Ther

https://doi.org/10.1007/s12325-019-00940-7

Unfortunately, the mean difference in change from baseline ACT was incorrectly reported in the abstract as 19.0 vs. 20.8 instead of 18.9 vs. 20.7

The original version of this article was revised.

The original article can be found online at https://doi. org/10.1007/s12325-019-00940-7.

J. Syk

Department of Neurobiology, Care Sciences and

Society, Karolinska Institutet, Stockholm, Sweden

J. Syk

Academic Primary Health Care Centre, Stockholm, Sweden

J. Syk

Department of Women's and Children's Health,

Uppsala University, Uppsala, Sweden

I. Vinge

Asthma-Allergy-Lung Department, Lidingö

Hospital, Lidingö, Sweden

M. Sörberg

Orion Pharma, Danderyd, Sweden

M. Vahteristo

Orion Corporation, Orion Pharma, Kuopio, Finland

P. Rytilä $(\varangle)$

Orion Corporation, Orion Pharma, Espoo, Finland

e-mail: paula.rytila@orionpharma.com
Open Access. This article is distributed under the terms of the Creative Commons Attribution-NonCommercial 4.0 International License (http://creativecommons.org/licenses/ by-nc/4.0/), which permits any noncommercial use, distribution, and reproduction in any medium, provided you give appropriate credit to the original author(s) and the source, provide a link to the Creative Commons license, and indicate if changes were made. 